\title{
POTENCIAL MUTAGÊNICO DO EXTRATO AQUOSO DE Piper tuberculatum
}

\author{
Thammyres de Assis Alves ${ }^{1}$ \\ Rondinelle Giordane da Costa ${ }^{2}$ \\ Maikon Keoma da Cunha Henrique ${ }^{3}$ \\ Thayllon de Assis Alves ${ }^{4}$ \\ Milene Miranda Praça-Fontes ${ }^{5}$
}

Resumo: A utilização de defensivos agrícolas sintéticos tem se intensificado cada vez mais a fim de manter a segurança alimentar. Entretanto, a medida que as aplicações vão sendo realizadas, esses defensivos vão apresentando decréscimo em sua eficácia. Além disso, há grandes debates acerca dos danos ambientais e à saúde humana que esses compostos químicos podem provocar. Assim é importante investir na busca por compostos naturais, com propriedades alelopáticas, que possam ser aplicados na agricultura, assegurando a produção agrícola e minimizando os impactos ambientais e à saúde humana. Diante do exposto, o objetivo do presente trabalho foi avaliar o efeito fitotóxico do extrato aquoso de Piper tuberculatum em Lactuca sativa. Para isso, avaliou-se a germinação e o crescimento de sementes da alface tratadas com diferentes concentrações do referido extrato. Os resultados obtidos demonstraram que o extrato aquoso de $P$. tuberculatum exerce efeito alelopático e mutagênico em alface, apresentando dessa forma, potencial para uso como bioherbicida.

Palavras-chave: Alface; Bioensaio; Fitotoxicidade.

\footnotetext{
${ }^{1}$ Mestranda em Genética e Melhoramento/Universidade Federal do Espírito Santo, Centro de Ciências Agrárias e Engenharias, Brasil, Alegre/ES. E-mail: thammyresalves@gmail.com.

2 Mestrando em Genética e Melhoramento/Universidade Federal do Espírito Santo, Centro de Ciências Agrárias e Engenharias, Brasil, Alegre/ES. E-mail: rondgiocosta@gmail.com.

3 Engenharia Florestal/ Universidade Federal do Espírito Santo, Centro de Ciências Agrárias e Engenharias, Brasil, Alegre/ES. E-mail: maikond2@gmail.com.

4 Agronomia/ Universidade Federal do Espírito Santo, Centro de Ciências Agrárias e Engenharias, Brasil, Alegre/ES. E-mail: thayllonalves@gmail.com.

5 Professora Adjunta/Universidade Federal do Espírito Santo, Centro de Ciências Exatas, Naturais e da Saúde CCENS -UFES/Departamento de Biologia, Alegre/ES. E-mail: milenemiranda@yahoo.com.br.
} 